\title{
Effects of Variations of Osmolarity on Behavior in Leptodactylus macrosternum Miranda-Ribeiro, 1926 (Leptodactylidae, Anura, Amphibia)
}

\author{
VANESSA MARIA GOMES BONFIM ${ }^{1,5}$, MARCELO FELGUEIRAS NAPOLI ${ }^{1,2}$, \\ ANDRÉ LUIS DA GRUZ ${ }^{1,2,3}$ AND WILFRIED KLEIN ${ }^{1,3,4}$
}

\begin{abstract}
Amphibians experiencing evapotranspirative water loss may suffer dehydration. Another difficulty is their limited tolerance to brackish water. This study aimed to investigate the effect of water salinity on behavior (activity and water conservation posture) in Leptodactylus macrosternum, in normally hydrated animals with urine in their bladder, in normally hydrated animals without urine in their bladder and in dehydrated ones with urine removed from their bladder. Experiments were filmed, behaviors were registered, and a Behavioral Dehydration Protection Index (BDPI) was calculated, using a weighted average of the postures. A GLM and Kruskall Wallis test was performed with Dunn's multiple comparisons test to evaluate the effects of osmotic gradient stress on BDPI. It was found that emptied bladder and aerial dehydration did not influence BDPI $(p=0.832$ and $p=0.142$, respectively), contrary to what is seen in the literature. The different osmotic media had a significant effect on BDPI $(\mathrm{p}=0.0003)$.
\end{abstract}

Keywords: Osmotic stress; Leptodacytulus macrosternum; conservation posture.

Anfíbios que experimentam perda de água podem sofrer desidratação. Outra dificuldade é a tolerância limitada à água salobra. Este trabalho teve como objetivo estudar o efeito da salinidade da água no comportamento (atividade e postura de conservação de água) de L. macrosternum, normalmente hidratados com urina armazenada na bexiga, normalmente hidratados com urina removida da bexiga e nos desidratados com urina removida da bexiga. Os experimentos foram filmados e foi calculado o índice de proteção comportamental da desidratação (BDPI) usando média ponderada. Realizamos modelo linear generalizado e teste Kruskall-Wallis com comparação múltipla de Dunn, para analisar o efeito dos gradientes de estresse osmótico sobre o BDPI. Observamos que a bexiga esvaziada e a desidratação exercida pelo ar não influenciam o aumento do BDPI $(\mathrm{p}=0.832$ e p = 0.142 , respectivamente) sendo contrário ao visto em literatura. Os diferentes meios osmóticos tiveram efeito sobre o BDPI ( $\mathrm{p}=$ $0.0003)$.

Palavras-chave: Estresse osmótico; Leptodacytulus macrosternum; postura de conservação.

\section{Introduction}

Amphibians possess specific traits, such as an integument with a great diffusion capacity resulting in great water loss by evapotranspiration, that are usually considered to make their survival in terrestrial environments more difficult, thereby explaining their dependence on water and preference for wet environments (Wygoda, 1984). Anurans can store water in specific body compartments such as the urinary bladder and use this water to regulate their body fluid homeostasis during periods of dehydration (McClanahan, 1967). The osmoregulatory organs that take an active part in the mechanisms that respond to stressful environmental conditions, such as restrictions in water availability

\footnotetext{
Programa de Pós-graduação em Diversidade Animal, Universidade Federal da Bahia, Rua Barão de Jeremoabo, Campus Universitário de Ondina, 40170-115 Salvador, Bahia, Brasil.

2 Departamento de Zoologia, Instituto de Biologia, Universidade Federal da Bahia, Rua Barão de Jeremoabo, Campus Universitário de Ondina, 40170-115 Salvador, Bahia, Brasil.

3 Instituto Nacional de Ciência e Tecnologia em Fisiologia Comparada, Universidade Estadual Paulista, Rio Claro, São Paulo, Brasil.

4 Universidade de São Paulo, Faculdade de Filosofia Ciências e Letras de Ribeirão Preto, Depto de Biologia, Avenida Bandeirantes 3900, Monte Alegre, 14040-901 Ribeirão Preto, São Paulo, Brasil.

5 Corresponding author: vmg.bonfim@gmail.com
} 
or osmotically different external media, participate in homeostatic regulation to adjust internal osmotic conditions in order to cope with environmental changes (Katz, 1989). One such organ is the urinary bladder, which is capable of storing water as diluted urine (McClanahan, 1967) and under osmotic stress, water can be withdrawn from the bladder back into the extracellular space to balance the loss of water (Shoemaker and Nagy, 1977). Another aspect of anuran ecophysiology is their limited tolerance to brackish water, indicated by the inability of many species to survive in highly saline environments. The ability to obtain water from the environment for fluid homeostasis is limited when exposed to isoosmotic or hyperosmotic solutions (Ruibal, 1959).

Amphibians are a useful model for studying the osmoregulatory system due to their great taxonomic and biological diversity, and also because they are found in highly different environments and subjected to very different types of stresses. These traits make it possible to understand the morphological and physiological adaptations present in this group (Burggren, 1999; Burggren and Warburton, 2007) and these adaptations may also be associated to specific behavioral responses. Species which do not present either physiological or morphological adaptations, to cope with water loss by evapotranspiration, may use behavioral responses as an important mechanism to resist dehydration (Wells, 2007). Among the many water saving behavioral aspects, the following stand out (Stille, 1958): 1) activity period, which is mostly nocturnal for anurans; avoiding high temperatures and low humidity during the day; 2) spatial distribution through habitat and micro-habitat choice, because amphibians that are less tolerant to dehydration are found mostly in regions with elevated humidity or near water bodies (Pough et al., 1977; Bastazini et al., 2007; Xavier and Napoli, 2011; Dabés et al., 2012); 3) aggregation of newly metamorphosed individuals on salamander adults; reducing the exposed surface area when under water stress (Rohr et al., 2002); 4) fossorial habit - occupying holes in the ground dug by other animals or by the amphibians themselves (Shoemaker and Nagy, 1977; Toledo and Jared, 1993; Warburg, 1997; Cartledge et al., 2006; Wells, 2007).

However, the most common behavioral response of anurans is the water conservation posture, characterized by compressing the entire ventral surface of the body against the substrate and gathering the limbs ventrally and laterally against the body (Pough et al., 1983; Hillyard et al., 1998). This posture reduces the surface area exposed to diffusional exchanges with the air, thereby reducing evapotranspirative water loss (Pough et al., 1983; Hillyard et al., 1998). Pough et al. (1983), while studying the reproductive site of the anuran Eleuterodactylus coqui, observed the water conservation posture and its variations during wet and dry periods and found that, depending on the air humidity, the anuran can adopt a more extreme water conservation posture, or derived postures with higher exposure.

Most studies on water balance and behavior use anurans from temperate climates, and neotropical anurans may possess specific adaptations (Navas et al., 2004; Dabés et al., 2012). This study focuses on Leptodactylus macrosternum, a semi-aquatic frog found in the tropical region of South America, which like most species of genus Leptodactylus can be found in terrestrial habitats, but needs open water to reproduce (Heyer, 1969), (Heyer and Giaretta, 2009). Andrade et al. (2012) recorded the presence of $L$. macrosternum in the Brazilian Northwest, in mangrove regions where the local salinity may vary from $20 \%$ of the sea water saline concentration, during the low tide, to $40 \%$ of the seawater saline concentration during the high tide. Leptodactylus macrosternum's type locality is the city of Salvador in the State of Bahia and the macro region of Salvador comprises mostly an Atlantic Forest landscape (Heyer and Giaretta, 2009). This species is considered to be generalist, adapted to open habitats and also to dry areas of tropical rainforests, and may also be found in environments under strong anthropic influence (Heyer and Giaretta, 2009). The aim was to study the effect of an osmotic gradient on the behavioral pattern of L. macrosternum, in order to achieve this the animals were dehydrated and rehydrated under different osmotic conditions, thereby assessing the influence of the different osmolarities on the animals' behavior, in particular their water conservation posture.

\section{Materials And Methods}

\section{Animal capture}

Leptodactylus macrosternum ( $\mathrm{N}=40$ ) was actively captured in the field during the night at Sítio [do Conde], in the municipality of Conde (Coordinates: $11^{\circ} 51^{\prime} 12,77^{\prime \prime} \mathrm{S} / 37^{\circ} 34^{\prime} 15,54^{\prime \prime} \mathrm{W}$ ), and at Arembepe, in the municipality of Camaçari (Coordinates: $12^{\circ}$ $46^{\prime} 18,6^{\prime \prime} \mathrm{S} / 38^{\circ} 10^{\prime} 46,8^{\prime \prime} \mathrm{W}$ ), both in the State of Bahia, Northeastern Brazil, under the environmental license SISBIO/ICMBIO No 36300-1. Transport, 
maintenance and experimentation were conducted according to license CEUA IBIO/UFBA 07/2012 from the Animal Experimentation Ethics Committee of the "Universidade Federal da Bahia".

\section{Laboratory Maintenance of the Anurans}

The animals were transported in individual plastic containers, containing a wet substrate and refuges. In the laboratory, the animals were kept together in a glass terrarium with water available ad libitum and refuges, and kept under a natural cycle of light and temperature. They were force-fed with dry dog food every second day. The animals were kept for a 30-day acclimatization period, and feeding was interrupted two days before experimentation.

\section{Experimental protocol}

According to Pough et al. (1983) the following behavioral categories were used: a) water conservation posture, in which an individual has its entire ventral region pressed against the substrate and limbs held tight against the body; b) chin up posture, in which the individual holds its ventral surface against the substrate except for the gular region, with limbs held close to the body; c) low alert posture, in which the individual presses the pelvic and abdominal region against the substrate, with hind limbs held close to the body and forelimbs elevating the body's cranial regions; d) high alert posture, in which the individual presses only the pelvic region against the substrate, with hind limbs close to the body and forelimbs elevating the rest of the body; e) vocalization posture, in which the individual touches the ground only with its hands and feet; and f) walking behavior, in which the individual walks touching the floor with feet and hands only. These kinds of behavior were further grouped in two major categories: g) conservation behavior, comprised of behavioral categories $\mathrm{a}, \mathrm{b}$, and $\mathrm{c}$; and $\mathrm{h}$ ) exposure behavior, comprised of behavioral categories $\mathrm{d}$, e, and $\mathrm{f}$.

The following experimental groups were used (Figure 1): A) no dehydration and no abdominal compression (it was assumed that animals which did not undergo abdominal compression had urine stored in their bladders) as the control group; B) no dehydration and with abdominal compression (empty bladder); G) with dehydration and with abdominal compression.

Each of these experimental groups was subjected to different osmotic treatments for a period of 30 minutes: 0) deionized water, 1) tap water, 2.5) a solution of sea water diluted to a salinity of 2.5

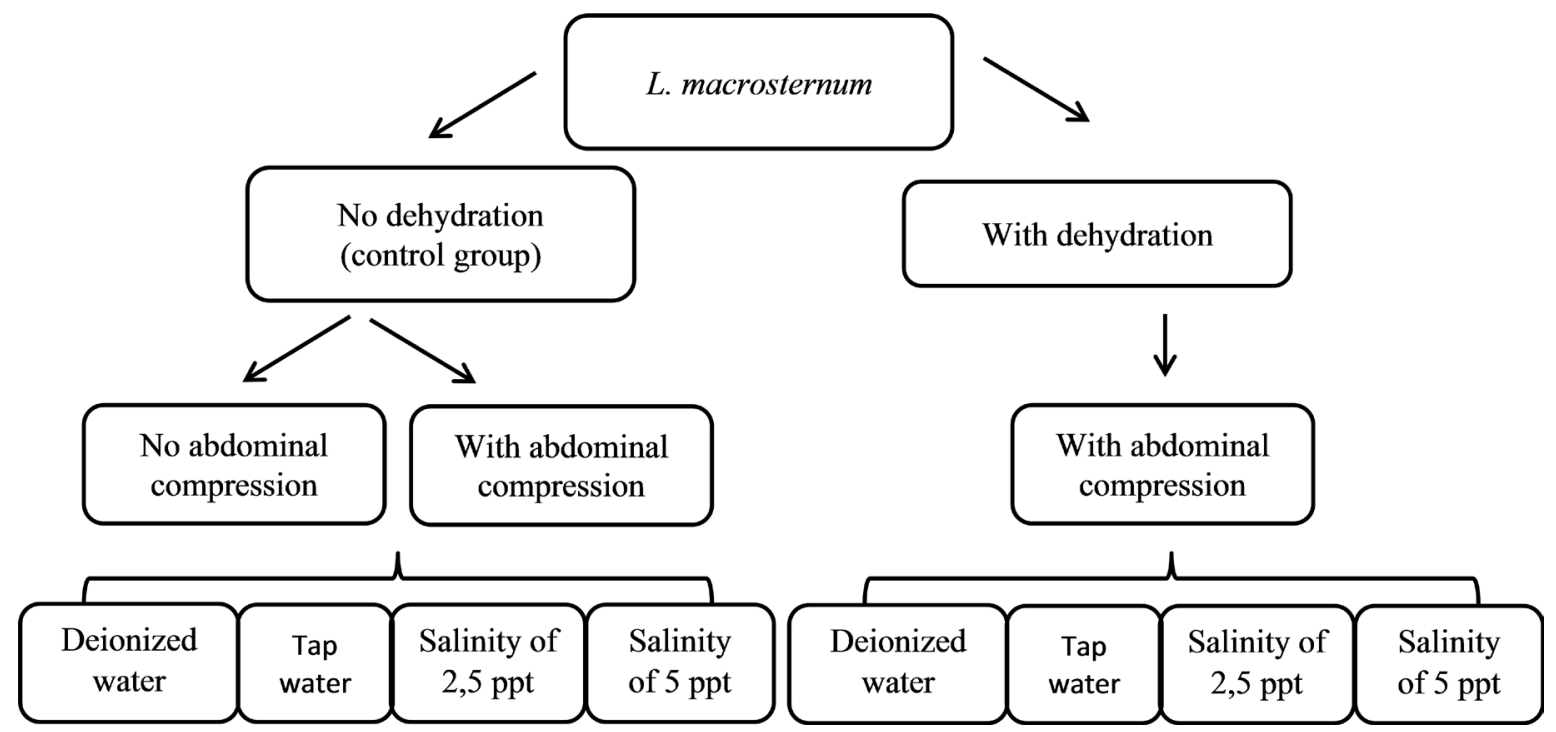

Figure 1. Experimental protocol (osmotic combinations): A) no dehydration and no abdominal compression (it was assumed that animals that had not suffered compression had urine in their bladders) as control group; B) No dehydration and with abdominal compression (no urine in bladder); $\mathrm{G}$ ) with dehydration and abdominal compression. For each of those combinations, different media were used for rehydration: 0) deionized water, 1) tap water, 2.5) solution of sea water with salinity 2.5 parts per thousand (ppt) and 5) solution of sea water with salinity of $5 p p t$, totalizing 12 combinations $\left(\mathrm{A}_{0}, \mathrm{~A}_{1}\right.$, $\mathrm{A}_{2.5}, \mathrm{~A}_{5}, \mathrm{~B}_{0}, \mathrm{~B}_{1}, \mathrm{~B}_{2.5}, \mathrm{~B}_{5}, \mathrm{C}_{0}, \mathrm{C}_{1}, \mathrm{C}_{2.5}, \mathrm{C}_{5}$, respectively). The sample size was six individuals per combination. 
parts per thousand (ppt), and 5) a solution of sea water diluted to a salinity of $5 \mathrm{ppt}$, comprising a total of 12 experimental combinations $\left(\mathrm{A}_{0}, \mathrm{~A}_{1}, \mathrm{~A}_{2.5}, \mathrm{~A}_{5}\right.$, $\mathrm{B}_{0}, \mathrm{~B}_{1}, \mathrm{~B}_{2.5}, \mathrm{~B}_{5}, \mathrm{C}_{0}, \mathrm{C}_{1}, \mathrm{C}_{2.5}, \mathrm{C}_{5}$, respectively). The sample size for each osmotic combination was six individuals, with some individuals being repeated used between experiments. However, whenever an experiment needed repetition of individuals, a recovery interval was applied: for individuals that suffered dehydration, there was a seven-day interval between experiments, and for those that were not dehydrated, the interval was four days long. All experiments were recorded for the 30 minutes of exposure to the different osmotic treatments using four digital compact cameras (Compact Digital Camera Sony $5 \mathrm{MP})$.

The animals that underwent dehydration during their experiments were dehydrated using a constant flow of air from an electric fan ("Mondial" brand V15 30cm with three speeds). Evaporative water loss was determined based on loss of body mass (Semi Analytical Precision Scale 0,01g), weighing individuals every 60 minutes.
Individuals were kept in chambers made out of metal mesh allowing exposure of the entire body surface. When an animal had lost $20 \%$ of its body mass, it was removed from the dehydration process and put in a rehydration chamber. Choosing a $20 \%$ loss of body mass as a cut-off point is in accordance with Cartledge et al. (2006), who found that such a percentage loss of body mass does no cause permanent physiological damage to the individuals.

\section{Data Analysis}

Total duration (in seconds) of each behavior was obtained for each individual of a given experimental treatment, this was achieved by adding the duration of all periods in which the individual exhibited that behavior, and those durations were converted into percentages of total time exposed to rehydration (Table 1). All videos were analyzed twice using a microcomputer (Microsoft Windows 7 using Media Player Software), first for observer training and then for data extraction.

Table 1. Mean, standard deviation, minimum and maximum times ( $\%$ of total observation time) of each behavior (a-f) and combined protection $(\mathrm{g})$ and exposure $(\mathrm{h})$ behaviors for each experimental group in each osmotic treatment $\left(\mathrm{A}_{0}, \mathrm{~A}_{1}, \mathrm{~A}_{2.5}, \mathrm{~A}_{5}\right.$, $\mathrm{B}_{0}, \mathrm{~B}_{1}, \mathrm{~B}_{2.5}, \mathrm{~B}_{5}, \mathrm{C}_{0}, \mathrm{C}_{1}, \mathrm{C}_{2.5}, \mathrm{C}_{5}$. Sample size was six individuals per treatment

\begin{tabular}{|c|c|c|c|c|c|c|c|c|}
\hline Treatment & $\mathbf{a}$ & $\mathbf{b}$ & $\mathbf{c}$ & d & $\mathbf{e}$ & $\mathbf{f}$ & $\mathrm{g}$ & $\mathbf{h}$ \\
\hline \multirow{2}{*}{$\mathrm{A}_{0}$} & $16.1 \pm 26.77$ & $58.22 \pm 32.84$ & $13.88 \pm 15.66$ & $1.43 \pm 2.23$ & $0.53 \pm 0.47$ & $9.84 \pm 12.71$ & $88.2 \pm 12.51$ & $11.8 \pm 12.51$ \\
\hline & $(0-66.67)$ & $(15.78-97.5)$ & $(0-40)$ & $(0-5.56)$ & $(0-1.11)$ & $(0-32.78)$ & (66.72-98.89) & $(1.11-33.28)$ \\
\hline \multirow{2}{*}{$\mathrm{A}_{1}$} & $10.1 \pm 17.75$ & $48.15 \pm 26.44$ & $15.52 \pm 6.69$ & $0.88 \pm 0.99$ & $10.63 \pm 12.87$ & $14.72 \pm 12.78$ & $73.77 \pm 20.72$ & $26.23 \pm 20.72$ \\
\hline & $(0-43.56)$ & $(9.39-79.5)$ & $(7.94-24.56)$ & $(0-2.61)$ & $(0-34.22)$ & $(0-29.94)$ & (33.94-88.56) & (11.44-66.06) \\
\hline \multirow{2}{*}{$\mathrm{A}_{2.5}$} & $15.53 \pm 11.89$ & $57 \pm 13.02$ & $10.55 \pm 14.05$ & $4.46 \pm 4.17$ & $3.09 \pm 2.18$ & $9.37 \pm 9.28$ & $83.07 \pm 9.34$ & $16.93 \pm 9.34$ \\
\hline & $(1.44-31.78)$ & $(47.94-82.78)$ & $(0.5-37.06)$ & $(0.67-12.61)$ & $(0-5.94)$ & $(0.22-21.28)$ & $(69.83-94)$ & $(6-30.17)$ \\
\hline \multirow{2}{*}{$\mathrm{A}_{5}$} & $59.69 \pm 23.69$ & $27.69 \pm 19.61$ & $0.98 \pm 7.3$ & $0.98 \pm 1.36$ & $1.87 \pm 2.1$ & $5.02 \pm 8.85$ & $92.13 \pm 11.62$ & $7.87 \pm 11.62$ \\
\hline & $(32.44-98.44)$ & $(1.56-56.72)$ & $(0-18.78)$ & $(0-2.83)$ & $(0-4.61)$ & $(0-22.83)$ & $(69.72-100)$ & $(0-30.28)$ \\
\hline \multirow{2}{*}{$\mathrm{B}_{0}$} & $13.83 \pm 12.89$ & $41.4 \pm 26.35$ & $10.7 \pm 10.17$ & $2.35 \pm 3.51$ & $3 . .64 \pm 3.14$ & $28.07 \pm 27.15$ & $65.94 \pm 30.78$ & $34.06 \pm 30.78$ \\
\hline & $(0-34.28)$ & $(13.39-79.28)$ & $(0-23.33)$ & $(0-8)$ & $(0-8.17)$ & $(4.06-64.72)$ & $(19.11-92.61)$ & $(7.39-80.89)$ \\
\hline \multirow{2}{*}{$\mathrm{B}_{1}$} & $30.53 \pm 39.61$ & $11.28 \pm 14.15$ & $3.81 \pm 18.02$ & $19.45 \pm 37.81$ & $3.81 \pm 8.54$ & $16.24 \pm 13.4$ & $60.49 \pm 37.47$ & $39.51 \pm 37.47$ \\
\hline & $(0-34.28)$ & $(0-42.06)$ & $(0-46.83)$ & $(0-95.89)$ & $(0-21.22)$ & $(4.11-32.61)$ & $(0-95.44)$ & $(4.56-100)$ \\
\hline \multirow{2}{*}{$\mathrm{B}_{2.5}$} & $50.03 \pm 42.88$ & $32.18 \pm 32.56$ & $8.73 \pm 19.42$ & $2.56 \pm 3.98$ & $1.96 \pm 4.41$ & $4.54 \pm 8.53$ & $90.94 \pm 15.95$ & $9.06 \pm 15.95$ \\
\hline & $(0-100)$ & $(0-79.94)$ & $(0-48.22)$ & $(0-8)$ & $(0-10.94)$ & $(0-21.72)$ & $(59.33-100)$ & $(0-40.67)$ \\
\hline \multirow{2}{*}{$\mathrm{B}_{5}$} & $56.53 \pm 30.61$ & $29.09 \pm 23.83$ & $7.58 \pm 11.22$ & $0 \pm 0$ & $1.93 \pm 2.6$ & $4.87 \pm 3.94$ & $93.2 \pm 4.47$ & $6.8 \pm 4.47$ \\
\hline & $(0-88)$ & $(0.83-70.28)$ & $(0.94-29.72)$ & $(0-0)$ & $(0-6.44)$ & $(0-10.67)$ & $(88.78-100)$ & $(0-11.22)$ \\
\hline \multirow{2}{*}{$\mathrm{C}_{0}$} & $39.41 \pm 43.34$ & $28.53 \pm 32.82$ & $17.44 \pm 26.85$ & $7.17 \pm 13.84$ & $4.93 \pm 11.93$ & $2.53 \pm 5.59$ & $85.38 \pm 31.24$ & $14.62 \pm 31.24$ \\
\hline & $(0-82.5)$ & $(8.61-94.28)$ & $(2.17-71.67)$ & $(0-35.06)$ & $(0-29.28)$ & $(0-13.89)$ & $(21.78-100)$ & $(0-78.22)$ \\
\hline \multirow{2}{*}{$\mathrm{C}_{1}$} & $16.28 \pm 20.2$ & $45.5 \pm 42.59$ & $14.92 \pm 21.9$ & $17.31 \pm 37.97$ & $4.72 \pm 10.49$ & $1.27 \pm 1.45$ & $76.69 \pm 36.62$ & $23.31 \pm 36.62$ \\
\hline & $(0-29.33)$ & $(0-100)$ & $(0-56.44)$ & $(0-94.72)$ & $(0-26.11)$ & $(0-3.22)$ & $(5.28-100)$ & $(0-94.72)$ \\
\hline \multirow{2}{*}{$\mathrm{C}_{2.5}$} & $25.89 \pm 28.7$ & $60.96 \pm 30.93$ & $1.49 \pm 1.71$ & $1.52 \pm 2.43$ & $2.36 \pm 3.57$ & $7.78 \pm 16.91$ & $88.34 \pm 21.18$ & $11.66 \pm 21.18$ \\
\hline & $(0-61.94)$ & $(32.22-100)$ & $(0-3.89)$ & $(0-5.5)$ & $(0-8.61)$ & $(0-42.22)$ & $(45.56-100)$ & $(0-54.44)$ \\
\hline \multirow{2}{*}{$\mathrm{C}_{5}$} & $64.54 \pm 25.92$ & $29.54 \pm 23.98$ & $5.1 \pm 8.06$ & $0 \pm 0$ & $0.22 \pm 0.54$ & $0.6 \pm 1.47$ & $99.18 \pm 2.02$ & $0.82 \pm 2.02$ \\
\hline & $(35.28-95.06)$ & $(0-63.33)$ & $(0-17.83)$ & $(0-0)$ & $(0-1.33)$ & $(0-3.61)$ & $(95.06-100)$ & $(0-4.94)$ \\
\hline
\end{tabular}


From the time duration percentages for each behavior the Behavioral Dehydration Protection Index (BDPI) was calculated. This index was calculated by applying weights to the time duration percentages of each of the postures (weights: $\mathrm{a}=6 ; \mathrm{b}=5 ; \mathrm{c}=4 ; \mathrm{d}=3 ; \mathrm{e}=2 ; \mathrm{f}=$ 1). The BDPI was the weighted average of these values. BDPI was calculated for each individual in each treatment. For each osmotic combination, the mean BDPI was calculated across all individuals in that combination and its standard deviation (Table 2). In order to analyze the effect of the predictor variables (dehydration, absence of urine in the bladder before rehydration and osmotic rehydration media) on the response variable

Table 2. Mean, standard deviation, minimum and maximum values of the Behavioral Dehydration Protection Index (BDPI) for each osmotic combination (A, B and C)

\begin{tabular}{|c|c|}
\hline Treatment & $\operatorname{BDPI}($ Mean \pm SD $)$ \\
\hline & $21.83 \pm 3.38$ \\
\hline \multirow[t]{2}{*}{$\mathrm{A}_{0}$} & $(17.55-26.83)$ \\
\hline & $19.15 \pm 4.02$ \\
\hline \multirow[t]{2}{*}{$\mathrm{A}_{1}$} & $(11.94-23.4)$ \\
\hline & $21.4 \pm 2.28$ \\
\hline \multirow{2}{*}{$\mathrm{A}_{2.5}$} & $(18.6-23.94)$ \\
\hline & $25.11 \pm 3.17$ \\
\hline \multirow[t]{2}{*}{$\mathrm{A}_{5}$} & $(19.18-28.5)$ \\
\hline & $17.87 \pm 6.24$ \\
\hline \multirow[t]{2}{*}{$\mathrm{B}_{0}$} & $(9.28-24.12)$ \\
\hline & $19.24 \pm 6.13$ \\
\hline \multirow[t]{2}{*}{$\mathrm{B}_{0}$} & $(12.67-26.73)$ \\
\hline & $24.39 \pm 5.05$ \\
\hline \multirow[t]{2}{*}{$\mathrm{B}_{2.5}$} & $(15.05-28.57)$ \\
\hline & $24.94 \pm 1.61$ \\
\hline \multirow[t]{2}{*}{$\mathrm{B}_{5}$} & $(22.39-27.11)$ \\
\hline & $22.99 \pm 5.68$ \\
\hline \multirow[t]{2}{*}{$\mathrm{C}_{0}$} & $(13.02-27.63)$ \\
\hline & $21.31 \pm 4.13$ \\
\hline \multirow[t]{2}{*}{$\mathrm{C}_{0}$} & $(15.04-24.76)$ \\
\hline & $23.01 \pm 4.37$ \\
\hline \multirow[t]{2}{*}{$\mathrm{C}_{2.5}$} & $(14.58-26.63)$ \\
\hline & $26.49 \pm 1.3$ \\
\hline $\mathrm{C}_{5}$ & $(24.88-28)$ \\
\hline
\end{tabular}

(BDPI), the normality and homoscedasticity of the data was tested first, this was in order to choose the proper statistical test. Then Shapiro-Wilk tests and and Levene tests were performed, for normality and homoscedasticity of the data, respectively. The Shapiro-Wilk test gave p-values of $p=0.03$ and $p=0.04$ for groups $\mathrm{C} 1$ and $\mathrm{C} 2.5$, and $\mathrm{p}>0.05$ for all other groups, indicating that those two groups did not follow a normal distribution. Levene's test gave a $p$-value of $p>0.308$ for all groups, indicating homoscedasticity. Thus, a generalized linear model (GLM, see Quinn and Keough, 2002) was chosen for use. This test was chosen due to the lack of normality of our data, it was not possible to use a standard multivariate ANOVA. GLM does not have premises of normality and homoscedasticity, and allows comparison of the effect of the predictor variables on the response ones by eliminating interactions between predictors. So as to compare whether there was significant difference in BDPI along the osmotic stress gradient or not, a non-parametric KruskalWallis test was performed followed by a Dunn's Multiple comparison test. A $\mathrm{P}<0.05$ was considered significant for all tests.

\section{Results}

The behaviors described by Pough et al. (1983) were all observed during this study, and duration of behaviors varied between treatments (Figure 2). Protection postures (a, b, and c) showed the longest time duration (Figure 3), but there was large individual variation (Table 1). This variation decreases as osmolarity increases, in the direction of the possible increase in osmoregulatory stress, from the least stressing osmotic medium, tap water, through deionized water and then the sea water solutions. This is seen in all combinations of factors. The same is seen for the BPDI (Figure 4).

Dehydration had no significant influence on posture duration (GLM, $\mathrm{p}=0.142$ ). Absence of urine in the bladder also did not significantly influence posture duration (GLM, $\mathrm{p}=0.832$ ). Osmotic media did significantly influence posture duration for the individuals (GLM, p = 0.0003; Kruskall-Wallis, $\mathrm{p}=$ 0.008), due to the large individual variations, however, Dunn's non parametric multiple comparisons test did not identify a significant difference between the treatments. 


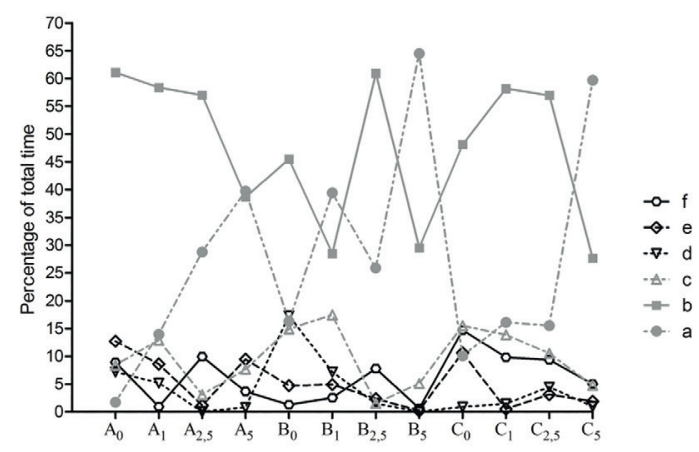

Figure 2. Average duration ( $\%$ of total duration) of behaviors observed ( $a, b, c, d, e, f)$, in a percentage of total time, for each treatment $\left(\mathrm{A}_{0}, \mathrm{~A}_{1}, \mathrm{~A}_{2.5}, \mathrm{~A}_{5}, \mathrm{~B}_{0}, \mathrm{~B}_{1}, \mathrm{~B}_{2.5}\right.$, $\mathrm{B}_{5}, \mathrm{C}_{0}, \mathrm{C}_{1}, \mathrm{C}_{2.5}, \mathrm{C}_{5}$ ). The sample size was six individuals per combination. For clarity of visualization, no standard deviations have been plotted.

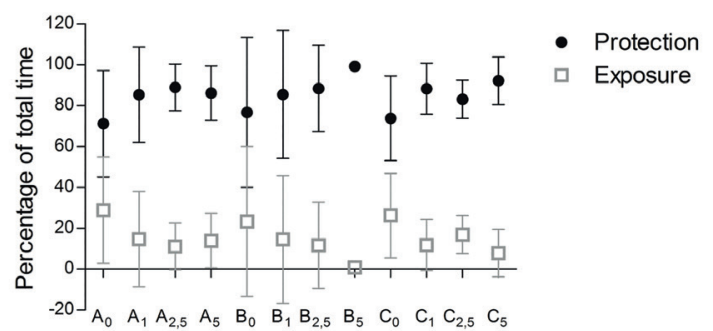

Figure 3. Average and standard deviations of durations of protection (a to c) and exposure ( $\mathrm{d}$ to $\mathrm{f}$ ) behaviors (\% of total time), for each treatment $\left(\mathrm{A}_{0}, \mathrm{~A}_{1}, \mathrm{~A}_{2.5}, \mathrm{~A}_{5}, \mathrm{~B}_{0}, \mathrm{~B}_{1}, \mathrm{~B}_{2.5}\right.$, $\left.\mathrm{B}_{5}, \mathrm{C}_{0}, \mathrm{C}_{1}, \mathrm{C}_{2.5}, \mathrm{C}_{5}\right)$. Points are the average value for the individuals and vertical bars are standard deviation. The sample size was six individuals per combination.

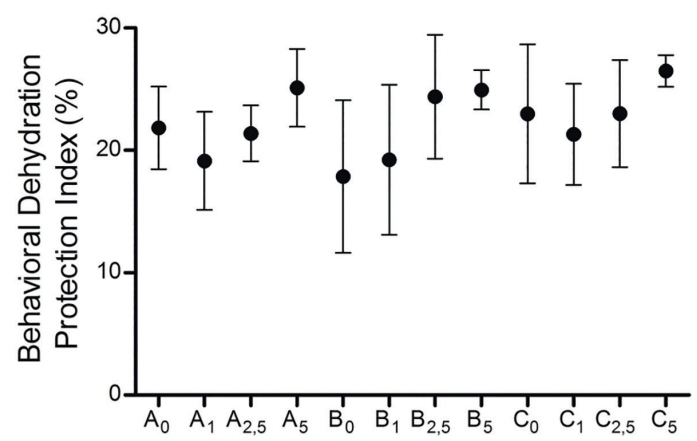

Figure 4. Average and standard deviations of Behavioral Dehydration Protection Index (BDPI) for each treatment $\left(\mathrm{A}_{0}, \mathrm{~A}_{1}, \mathrm{~A}_{2.5}, \mathrm{~A}_{5}, \mathrm{~B}_{0}, \mathrm{~B}_{1}, \mathrm{~B}_{2.5}, \mathrm{~B}_{5}, \mathrm{C}_{0}, \mathrm{C}_{1}, \mathrm{C}_{2.5}, \mathrm{C}_{5}\right.$. Points are the average value for the individuals and vertical bars are standard deviation. The sample size was six individuals per combination.

\section{Discussion}

The reduced variation in duration of protection behavior shows that even though the statistical tests did not detect significant difference between treatments, in a general manner, L. macrosternum remained in protective postures for longer times as the osmotic stress increased within the treatments. From this, we can infer that greater osmotic concentrations in surrounding water are physiologically stressful for this species. It is known that dehydration stress (in this study, caused by air or saline media) is an important factor for the increase of frequency or duration of postures associated with water conservation in anurans (Heatwole et al., 1969; Brekke et al., 1991; Hillyard et al., 2007; Pough et al., 1983; Hillyard et al., 1998; Prates et al., 2013; Taylor et al., 1999; Viborg and Rosenkilde, 2001; Tran et al., 1992) Hillyard et al. (1998), while studying the physiological processes involved in the behavioral response of Bufo marinus, normally hydrated as well as dehydrated (loss of $10 \%$ of initial body mass), and rehydration in $\mathrm{NaCl}$ solutions with concentrations of $250 \mathrm{mmol} / \mathrm{L}$ and 500 $\mathrm{mmol} / \mathrm{L}$, saw that both groups exhibited the "ventral skin down" posture (equivalent to this study's "a" or water conservation posture), but the normally hydrated individuals kept themselves in this posture for a shorter time than individuals which were dehydrated.

Absence of urine in the bladder did not influence the behavioral response of L. macrosternum, which is contrary to what is seen in the literature, given that diluted urine in the bladder is said to be an important water reserve for amphibians from xeric environments with water restrictions through some periods of the year (Sinsch, 1991; Davis and DeNardo, 2007; Reynolds and Christian, 2009). Brekke et al. (1991), while studying water absorption behavior in individuals of Bufo punctatus (presently Anaxyrus punctatus) dehydrated, not dehydrated and with emptied bladder, found that dehydrated individuals with emptied bladder exhibited the water conservation posture more than individuals that suffered dehydration without having their bladders emptied.

Leptodactylus macrosternum's bladder size and its semi-aquatic habitat may have influenced the non-significance of this organ in this study. Even though this organ is expandable, bladder volume can vary according to the species and the habitat, and aquatic and semi-aquatic animals may not need a large water storage capacity, given that they are most of the time in or near water bodies (Wake, 1970; Jørgensen, 1997; Canziani and Cannata, 1980; Christensen, 
1974). Given this, the bladder would not have a direct influence on the behavioral response of $L$. macrosternum, which is a semi-aquatic animal, and therefore with little need for the bladder as a water reservoir.

Jorgensen (1994) suggests that there may be significant variation of an animal's real hydration state. For instance, in hydrated Bufo bufo, a terrestrial amphibian, the bladder urine volume varies up to $5 \%$ of the animal's average body mass, which the author interpreted as a spontaneous variation in hydration, suggesting that the animal's hydration may not use the bladder as its main rehydrational organ. Such a variation in hydration state suggests a highly dynamic water balance between the circulatory and lymphatic systems, kidneys (Jorgensen, 1994) and liver (Churchill and Storey, 1994).

It has also been suggested that, in long or severe dehydration periods, the water in diluted urine is used, and the urine's urea concentration rises, compared to the lymph and blood, but with continued dehydration those concentrations become equal, and the osmoregulatory organs become isosmotic (Balinsky et al., 1961; Ruibal, 1962; Cartledge et al., 2006; Reynolds and Christian, 2009). Scaphiopus couchi, a desert anuran, was studied regarding its ability to withstand dehydration and its body's urea and electrolyte balance (McGlanahan, 1967). When individuals of that species, without urine stored in the bladder, are slowly dehydrated, plasma osmolarity increases concomitantly with the frog's loss of body mass. The plasma concentration of Scaphiopus couchi with urine in the bladder varies during slow dehydration, and when the volume of water stored in the bladder (about $31 \%$ of total body mass) is decreased, that is, when the lost mass represents the depletion of the bladder's water reserves, the plasma concentration increases similarly to that of individuals without water stored in the bladder. Given this variable effect of the bladder, there may have been a variation of the volume of diluted urine stored in L. macrosternum's bladder, and the dehydration period caused by the saline media may have not been long enough to cause this water to have been completely absorbed, which may have caused the apparent absence of influence of the bladder on L. macrosternum's water conservation behavioral response.

\section{Conclusion}

The effect of different osmotic treatments on behavioral aspects showed that L. macrosternum has a tendency to assume a water conservation posture for longer periods when exposed to more stressful osmotic situations. However, it is necessary to study the osmotic concentrations, as well as the solute compositions of blood and urine to reach a better understanding of the water and ion balance of $L$. macrosternum, thereby better understanding the underlying principles of osmoregulatory behaviors.

The osmoregulatory system is important for the water balance in anurans, and the mechanisms that detect or control this balance should be better studied. To understand how the behavioral response is influenced by variations in osmolarity it is important to study the biochemical, physiological and morphological aspects of this control, especially the urinary bladder.

\section{References}

Andrade, E. B., Júnior, T. B. L., Júnior, J. M. A. L., and Leite, J. R. S. A. (2012). Predation by native fish and feeding by crab species on Leptodactylus macrosternum Miranda-Ribeiro, 1926 (Anura: Leptodactylidae) in northeastern, Brazil. Herpetology Notes, 5,173-175.

Balinsky, J. B., Cragg, M. M., and Baldwin, E. (1961). The adaptation of amphibian waste nitrogen excretion to dehydration. Comparative Biochemistry and Physiology, 3, 236-244.

Bastazini, C. V., Munduruca, J., Rocha, P., and Napoli, M. F. (2007). Amphibians from the restinga of Mata de São João, Bahia, Brazil: Which environmental variables are associated with the anuran composition. Herpetologica, 63, 459-471.

Brekke, D. R., Hillyard, S. D., and Winokur, R. M. (1991). Behavior associated with the water absorption response by the toad, Bufo punctatus. Copeia, 1991, 393-401.

Burggren, W. W. and Warburton, S. (2007). Amphibians as animal models for laboratory research in physiology. ILAR Journal, 48, 260-269.

Burggren, W. W. (1999). Developmental physiology, animal models, and the August Krogh principle. Zoology, 102, 148-156.

Canziani, G. A. and Cannata, M. A. (1980). Water balance in Ceratophrys ornata from two different environments. 
Comparative Biochemistry and Physiology, 66, 599603.

Cartledge, V. C., Withers, P. C., McMaster, K. A., Thompson, G. G., and Bradshaw, S. D. (2006). Water balance of field-excavated aestivating australian desert frogs, the cocoon-forming Neobatrachus aquilonius and the non-cocooning Notaden nichollsi (Amphibia: Myobatrachidae). The Journal of Experimental Biology, 209, 3309-21.

Christensen, C. U. 1974. Adaptations in the water economy of some anuran amphibia. Comparative Biochemistry and Physiology, 47(A), 1035-1049.

Churchill, T. A. and Storey, K. B. (1994). Effects of dehydration on organ metabolism in the frog Pseudacris crucifer: Hyperglycemic responses to dehydration mimic freezing-induced cryoprotectant production. Journal of Comparative Physiology, 164, 492-498.

Dabés, L., Bonfim, V., Napoli, M. F., and Klein, W. (2012). Water balance and spatial distribution of an anuran community from Brazil. Herpetologica, 68, 443-455.

Davis, J. R and DeNardo, D. F. 2007. The urinary bladder as a physiological reservoir that moderates dehydration in a large desert lizard, the Gila monster Heloderma suspectum. The Journal of Experimental Biology, 210, 1472-1480.

Heatwole, H., Torres, F., Blasini, D. A., and Heatwole, A. (1969). Studies on anuran water balance. I. Dynamics of evaporative water loss by the coquí, Eleutherodactylus portoricensis. Comparative Biochemistry and Physiology, 28, 245-69.

Heyer, W. R. (1969). The adaptive Ecology of the Species Groups of the Genus Leptodactylus (Amphibia, Leptodactylidae). Evolution, 23, 421-428.

Heyer, W. R. and Giaretta, A. A. (2009). Advertisement calls, notes on natural history, and distribution of Leptodactylus chaquensis (Amphibia: Anura: Leptodactylidae) in Brasil. Proceedings of the Biological Society of Washington, 122, 292-305.

Hillyard, S. D., Hoff, K. S., and Propper, C. (1998). The water absorption response: A behavioral assay for physiological processes in terrestrial amphibians. Physiological Zoology, 71, 127-38.
Hillyard, S. D., Baula, V., Tuttle, W., Willumsen, N. J., and Larsen, E. H. (2007). Behavioral and neural responses of toads to salt solutions correlate with basolateral membrane potential of epidermal cells of the skin. Chemical Senses, 32, 765-73.

Jorgensen, C. B. (1997). 200 years of amphibian water economy: From Robert Townsend to the present. Biology Review, 72, 153-237.

Jorgensen, C. B. (1994). Water economy in a terrestrial toad (Bufo bufo), with special reference to cutaneous drinking and urinary bladder function. Comparative Biochemistry and Physiology, 109, 311-324.

Katz, U. (1989). Strategies of adaptation to osmotic stress in Anuran Amphibia under salt and burrowing conditions. Comparative Biochemistry and Physiology, 93, 499-503.

McClanahan, L. (1967). Adaptations of the spadefoot toad Scaphiopus couchi, to desert environments. Comparative Biochemistry and Physiology, 20, 73-99.

Pough, F. H., Taigen, T. L., Stewart, M. M., and Brussard, P. F. (1983). Behavioral modification of evaporative water loss by a Puerto Rican frog. Ecology, 64, 244252.

Pough, F. H., Stewart, M. M., and Thomas, R. G. (1977). Physiological basis of habitat partitioning in jamaican Eleutherodactylus. Oecologia, 27, 285-293.

Prates, I., Angilleta, M. J., Wilson, R. S., Niehaus, A. C., and Navas, C. A. (2013). Dehydration hardly slows hopping toads (Rhinella granulosa) from xeric and mesic environments. Physiological and Biochemical Zoology, 86, 451-457.

Quinn, G. and Keough, M.J. (2002). Experimental Design and Data Analysis for Biologists.

Reynolds, S. J. and Christian, K. A.(2009). Environmental moisture availability and body fluid osmolality in introduced toads, Rhinella marina, in monsoonal northern Australia. Journal of Herpetology, 43, 326331.

Rohr, J. R., Madison, D. M., and Sullivan, A. M. (2002). The ontogeny of chemically-mediated antipredator behaviours in newts (Notophthalmus viridescens): 
Responses to injured and non-injured conspecifics. Behaviour, 139, 1043-1060.

Ruibal, R. (1959). The ecology of a brackish water population of Rana pipiens. Copeia, 1959, 315-322.

Ruibal, R. (1962). The adaptive value of bladder water in the toad, Bufo cognatus. Physiological Zoology, 35, 218-223.

Shoemaker, V. and Nagy, K. A. (1977). Osmoregulation in amphibians and reptiles. Annual Review of Physiology, 39, 449-471.

Sinsch, U. (1991). Reabsorption of water and electrolytes in the urinary bladder of intact frogs (Genus Rana). Comparative Biochemistry and Physiology, 99, 559-65.

Stille, W. T. (1958). The water absorption response of an anuran. Copeia, 217-218.

Taylor, K., Mayer, L. P., and Propper, C. R. (1999). Intraand extracellular dehydration-induced thirst-related behavior in an amphibian. Physiology and Behavior, $65,717-21$.

Toledo, R. C. and Jared, C. (1993). Cutaneous adaptations to water balance in amphibians. Comparative Biochemistry and Physiology, 10, 593-608.
Tran, D. Y., Hoff, K. V., and Hillyard, S. D. (1992). Effects of angiotensin II and bladder condition on hydration behavior and water uptake in the toad, Bufo woodhousei. Comparative Biochemistry and Physiology, 103, $127-$ 30 .

Viborg, A. L. and Rosenkilde, P.(2001). Angiotensin II elicits water seeking behavior and the water absorption response in the toad Bufo bufo. Hormones and Behavior, 39, 225-31.

Wake, M. H. (1970). Evolutionary Morphology of the Caecilian Urogenital System. Part III. The Bladder. Herpetologica, 26, 120-128.

Warburg, M. R. (1997). Ecophysiology of Amphibians Inhabiting Xeric Environments. Springer.

Wells, K. D. (2007). The Ecology and Behavior of Amphibians. The University of Chicago.

Wygoda, M. L. (1984). Low cutaneous evaporative water loss in arboreal frogs. Physiological Zoology, 57, 329337.

Xavier, A. L. and Napoli, M. F. (2011). Contribution of environmental variables to anuran community structure in the caatinga domain of Brazil. Phyllomedusa, 10, 45-64. 